'Instituto Agronômico de Pernambuco - IPA, Av. General San Martin, CEP 50761-000, Bongi, Recife, PE

*autor correspondente $\square$ regina.rosa@ipa.br

\title{
Doenças fúngicas em cultivos agroecológicos de hortaliças no Sertão do Pajeú Pernambucano, Brasil
}

\author{
Fungi diseases in Agroecological vegetable crops in the \\ Sertão do Pageú, Pernambuco, Brazil
}

Regina Ceres Torres da Rosa ${ }^{1}$, Luciana Melo Sartori Gurgel ${ }^{1}$,

Domingos Eduardo Guimarães Tavares Andrade', Tereza Cristina Assis ${ }^{1}$, Aleide Margarete Godê Vasconcelos ${ }^{1}$, Enildo Cardoso ${ }^{1}$

RESUMO: A ocorrência de doenças pode ser um dos fatores limitantes para cultivo de hortaliças orgânicas ou em fase de transição agroecológica. Assim, o estudo visou identificar as doenças causadas por fungos em hortaliças em fase de transição agroecológica no Sertão do Pajeú Pernambuco. O monitoramento foi realizado em quatro propriedades, dos municípios de Solidão e Tabira, por um período de um ano. As amostras de diferentes plantas doentes foram levadas ao laboratório para isolamento e identificação dos fitopatógenos. Os resultados obtidos mostram a ocorrência dos gêneros Fusarium, Puccinia, Oidium, Cercospora e Alternaria. As cercosporioses e alternarioses foram mais frequentes com percentuais de $35,3 \%$ e $29,4 \%$, respectivamente.

PALAVRAS-CHAVE: Ocorrência, fungos fitopatogênicos, levantamento.

\begin{abstract}
In recent years, there has been an increase in the consumption of organic vegetables and in the agroecological transition phase in the municipalities of the Sertão de Pernambuco. However, diseases can be a limiting factors of these productions. This study aimed to identify diseases in vegetables undergoing agroecological transition caused by fungi in the Sertão do Pajeú, Pernambuco. The occurrence of diseases was monitored in four properties in each municipality for a period of one year. Sick plants were taken to the Phytopathology Laboratory (IPA), for isolation and identification of phytopathogens. The results obtained show the occurrence of Fusarium sp., Puccinia sp. Oidium sp. Cercospora $s p$. and Alternaria sp. in the municipalities. The leaves spot caused by Cercospora and Alternaria were more frequent with percentages of $35.3 \%$ and $29.4 \%$, respectively.
\end{abstract}

KEYWORDS: Occurrence, phytopathogenic fungi, survey.

A agropecuária é um dos setores que se sobressaem na economia do Sertão do Pajeú, sendo predominante a agricultura de subsistência e de base familiar, apresentando cultivos temporário e permanente, das mais diversas culturas (CUENCA, 2007; BRASIL, 2011). Em 2018, a área plantada com cultivos temporários e permanente foi de aproximadamente $94.980 \mathrm{ha}$ e 960ha, respectivamente (INSTITUTO BRASILEIRO DE GEOGRAFIA E ESTATÍSTICA, 2020). Dentre os municípios desta região, Solidão e Tabira destacam-se com cultivo de algodão herbáceo, arroz, batata-doce, cana-de-açúcar, feijão, milho, mandioca, tomate e frutíferas (VERSYPLE et al., 2015). Nos últimos anos, foi crescente o consumo de hortaliças orgânicas ou em fase de transição agroecológica nesses municípios. Segundo Barroso et al. (2017), o incremento da demanda por alimentos saudáveis e produzidos de maneira 
sustentável tem sido requerido, por parte dos consumidores, ao setor hortícola mundial. Estes sistemas de cultivo dão ênfase ao manejo das relações biológicas, como aquelas entre pragas e predadores e em processos naturais, como a fixação biológica do nitrogênio ao contrário do uso de métodos químicos (BETTIOL, 2004). E o controle de pragas e doenças deve ser feito apenas quando houver possibilidade de danos consideráveis à produção. Antes, deve-se procurar o equilíbrio natural do agroecossistema, utilizando práticas promotoras da biodiversidade (SEDIYAMA et al., 2014). Nessa perspectiva, as diferentes estratégias de manejo de doenças devem ser adotadas de forma integrada (PEREIRA; PINHEIRO, 2012).

Nos sistemas agroecológicos, o impacto da ocorrência de patógenos nas plantas tem sido pouco estudado. Assim, faz-se necessário a obtenção de conhecimentos epidemiológicos para o desenvolvimento de um programa de manejo integrado de doenças de plantas, iniciando-se com o levantamento fitopatológico. As informações obtidas no levantamento de campo permitem avaliar a importância relativa de doenças, monitorar as populações nas suas intensidades, verificar a eficiência e a aceitação de práticas recomendadas para o controle (KING, 1980; SILVA et al., 2007; SILVA, 2015).

Em Pernambuco e Santa Catarina foram realizados os levantamentos da alternariose (A. brassicicola e A. brassicae) e da podridão-negra em cultivos orgânicos de brássicas, verificando-se que, embora as condições climáticas entre os estados fossem diferentes, não houve diferença na severidade de cada doença no conjunto de brássicas. Em Pernambuco, em $69 \%$ das amostras avaliadas foram detectadas $A$. brassicicola. Porém, na cultura da couve-manteiga, as duas espécies foram constatadas com frequência (PERUCH et al., 2006). Já nas produções urbanas de alface em Campina Grande/PB, as principais doenças detectadas foram cercosporiose e a septoriose, enquanto o míldio e a septoriose se destacaram em Lavras/MG. Neste estudo, independentemente da estação de cultivo, não foram verificadas diferenças para a severidade da cercosporiose. No entanto, no inverno e outono houve aumento da AACPD da septoriose. O oídio e a podridão-negra foram as doenças mais importantes no plantio da couve-manteiga, independente da região (SILVA, 2015). No levantamento de doenças foliares realizado em 21 hortas urbanas de Petrolina/PE, verificaram-se como principais doenças as bacterioses, viroses e oídios, com $29,5 \%, 14,31 \%$ e $12,90 \%$, respectivamente. Os autores afirmam que através desse levantamento podem-se determinar as prioridades da pesquisa/extensão e, também, indicar quais estratégias podem ser seguidas nas decisões de políticas públicas para reduzir problemas fitossanitários nas hortas urbanas locais (BARROSO et al., 2017). Diante do exposto, o trabalho teve como objetivo realizar o levantamento de doenças em hortaliças em fase de transição agroecológica, no período de um ano, em municípios do sertão do Pajeú, Solidão e Tabira, PE.

O levantamento foi realizado em quatro propriedades dos municípios de Solidão e Tabira, situados no Sertão do Pajeú, PE, no período de outubro de 2014 e setembro de 2015 (Tabela 1). Em cada propriedade, mensalmente foram coletadas amostras de diferentes partes de plantas doentes (caule, raiz e folhas), quando da observação dos sintomas e sinais de fitopatógenos nas hortaliças. A precipitação média, durante o período experimental, de Tabira e Solidão foi de $57,5 \mathrm{~mm}$ (variação mín. e máx. de 0-230,2mm) e 55,3mm (variação mín. e máx. de $0-253,0 \mathrm{~mm}$ ), respectivamente, com distribuição irregular da chuva dentro de cada mês, onde a maior precipitação ocorreu entre fev-abril de 2015 (AGÊNCIA PERNAMBUCANA DE ÁGUAS E CLIMA, 2020).

As amostras foram acondicionadas em sacos plásticos identificados, transportadas em ambiente refrigerado e enviadas para isolamento e identificação ao Laboratório de Fitopatologia do Instituto Agronômico de Pernambuco - IPA. A diagnose das doenças foi realizada inicialmente pela observação dos sintomas e sinais, com o auxílio de microscópio estereoscópico e ótico. Para as plantas cujos fitopatógenos não foram identificados diretamente, foi realizado o isolamento dos micro-organismos presentes nas partes doentes das plantas. Após as etapas iniciais de limpeza e desinfestação do material, fragmentos de áreas lesionadas (MENEZES; ASSIS, 2004) foram transferidos para placas de Petri contendo o meio de cultura BDA (batata, 200,0g; dextrose, 20,0g; agar, 17,0g; água destilada, 1L; suplementado com tetraciclina $(250 \mathrm{ppm})$, sendo então incubados a $25 \pm 2^{\circ} \mathrm{C}$, sob alternância luminosa - 12 horas de claro/12 horas de escuro). A identificação dos fitopatógenos foi realizada analisando as características morfológicas e reprodutivas, por meio de esteromicroscópio e através de lâminas temporárias visualizadas em microscópio óptico, com o auxílio de literatura específica (BARNET; HUNTER, 1972; NELSON et al., 1983; ALEXOPOULOS et al., 1996).

Foram registradas 18 espécies de hortaliças cultivadas pelos agricultores nos municípios estudados. De acordo com a Tabela 1, constatamos que a maioria dos agricultores produzem a alface (Lactuca sativa), cebolinha (Allium fistulosum), coentro (Coriandrum sativum), couve-folha (Brassica oleracea) e quiabo (Abelmoschus esculentus). Concordando com estudo de Barroso et al. (2017), que ao realizar o levantamento de doenças foliares em hortas urbanas em Petrolina/PE verificou que, das 21 hortas amostras analisadas em 64,0\% dos canteiros, as culturas plantadas pelos agricultores foram alface, cebolinha, coentro e couve.

Associados ao material sintomático das diferentes hortícolas, independente do município avaliado, foram identificados os seguintes gêneros: Fusarium, Puccinia, Oidium, Cercospora e Alternaria (Tabela 2). Destacamos esses dois últimos gêneros promovendo o desenvolvimento de doenças em percentuais de $35,3 \%$ e $29,4 \%$, respectivamente, em diferentes culturas (Figura 1), nos municípios estudados.

As condições ideais requeridas para o desenvolvimento das manchas de Cercospora ou cercosporioses são temperatura e umidade alta, condizentes com os dados observados naquela região (VERSYPLE et al., 2015). Além disso, uma característica importante verificada no ciclo de vida deste gênero é o tempo de sobrevivência em detritos de plantas no solo, que pode chegar até três anos, dependendo das condições climáticas (SOLEL, 1970). Por outro lado, as manchas de alternaria, em geral, podem apresentar alto poder destrutivo em condições de altas temperaturas e umidade. A ocorrência de epidemias severas dessa doença está sempre associada a temperaturas 
Tabela 1. Caracterização das propriedades dos municípios de Tabira e Solidão, Sertão do Pajeú, Pernambuco, Brasil.

\begin{tabular}{|c|c|c|c|}
\hline Município & Propriedade & Georreferência & Hortaliças cultivadas \\
\hline \multirow{8}{*}{ Solidão } & \multirow{2}{*}{1} & $07^{\circ} 34^{\prime} 12^{\prime} \mathrm{S}$ & \multirow{2}{*}{$\begin{array}{c}\text { Alface, Cebolinha, Cenoura, Coentro, Couve-folha, Pimentão, Pimenta de cheiro, } \\
\text { Quiabo, Rúcula, Repolho, Tomate, Tomate cereja, }\end{array}$} \\
\hline & & $37^{\circ} 40^{\prime} 41^{\prime \prime} \mathrm{W}$ & \\
\hline & \multirow{2}{*}{2} & $07^{\circ} 35^{\prime} 38^{\prime \prime} \mathrm{S}$ & \multirow{2}{*}{$\begin{array}{l}\text { Alface, Abobrinha, Cebolinha, Coentro, Couve-folha, Pepino, Pimentão, Pimenta-de- } \\
\text { cheiro, Quiabo }\end{array}$} \\
\hline & & $37^{\circ} 37^{\prime} 01^{\prime} \mathrm{W}$ & \\
\hline & \multirow{2}{*}{3} & $07^{\circ} 35^{\prime} 55^{\prime \prime} \mathrm{S}$ & \multirow{2}{*}{$\begin{array}{l}\text { Abobrinha, Alface, Berinjela, Beterraba, Cenoura, Cebolinha, Coentro, Couve-folha, } \\
\text { Minipepino, Pepino, Pimentão, Pimenta-de-cheiro, Pimenta-dedo-de-moça, Quiabo, } \\
\text { Rabanete, Salsinha, Tomate-cereja }\end{array}$} \\
\hline & & $37^{\circ} 41^{\prime} 09^{\prime \prime} \mathrm{W}$ & \\
\hline & \multirow{2}{*}{4} & $07^{\circ} 37^{\prime} 37^{\prime \prime} \mathrm{S}$ & \multirow{2}{*}{$\begin{array}{l}\text { Alface, Beterraba, Cebolinha, Cebola-branca, Coentro, Couve-folha, Pimentão, } \\
\text { Quiabo, Repolho, Rabanete, Rúcula, Tomate, Tomate-cereja }\end{array}$} \\
\hline & & $37^{\circ} 44^{\prime} 33^{\prime \prime} \mathrm{W}$ & \\
\hline \multirow{8}{*}{ Tabira } & \multirow{2}{*}{1} & $07^{\circ} 36^{\prime} 10,72 ” S$ & \multirow{2}{*}{$\begin{array}{c}\text { Abobrinha, Coentro, Cebolinha, Couve-folha, Cenoura, Berinjela, Pimenta-de-cheiro, } \\
\text { Quiabo }\end{array}$} \\
\hline & & $37^{\circ} 29^{\prime} 40^{\prime \prime} \mathrm{W}$ & \\
\hline & \multirow{2}{*}{2} & $07^{\circ} 29^{\prime} 34,39^{\prime} \mathrm{S}$ & \multirow{2}{*}{ Alface, Cebolinha, Coentro, Couve-folha, Pimentão } \\
\hline & & $37^{\circ} 28^{\prime} 15,52^{\prime \prime} \mathrm{W}$ & \\
\hline & \multirow{2}{*}{3} & $07^{\circ} 32^{\prime} 16,63 ” \mathrm{~S}$ & \multirow{2}{*}{ Alface, Cebolinha, Coentro, Couve-folha, Quiabo, Pimenta-malagueta, Pimentão } \\
\hline & & $37^{\circ} 32^{\prime} 22,95^{\prime \prime} \mathrm{W}$ & \\
\hline & \multirow{2}{*}{4} & $07^{\circ} 32 ’ 13,63 ” \mathrm{~S}$ & \multirow{2}{*}{ Alface, Coentro, Pimenta-de-cheiro, Pepino, Quiabo } \\
\hline & & $37^{\circ} 32^{\prime} 22,95^{\prime \prime} \mathrm{W}$ & \\
\hline
\end{tabular}

Tabela 2. Doenças fúngicas detectadas em cultivos de hortaliças em fase de transição agroecológica nos municípios de Tabira e Solidão.

\begin{tabular}{|c|c|c|c|}
\hline CULTURA & $\begin{array}{c}\text { DOENÇA } \\
\text { (NOME COMUM) }\end{array}$ & PATÓGENO & MUNICÍPIO \\
\hline Abobrinha & $\begin{array}{l}\text { Podridão das raízes e do colo/ } \\
\text { Murcha de Fusário }\end{array}$ & Fusarium sp. & Solidão \\
\hline Alface & $\begin{array}{l}\text { Mancha de cercospora/ } \\
\text { Cercosporiose }\end{array}$ & Cercospora sp. & Solidão \\
\hline Berinjela & $\begin{array}{c}\text { Mancha de Alternaria/ Pinta preta/ } \\
\text { Alternariose }\end{array}$ & Alternaria sp. & Solidão \\
\hline Beterraba & $\begin{array}{l}\text { Mancha de cercospora/ } \\
\text { Cercosporiose }\end{array}$ & Cercospora sp. & Tabira \\
\hline Cebolinha & $\begin{array}{l}\text { Mancha púrpura/ Mancha de } \\
\text { alternaria }\end{array}$ & Alternaria sp. & Tabira \\
\hline Pepino & $\begin{array}{c}\text { Mancha de Alternaria/ } \\
\text { Alternariose }\end{array}$ & Alternaria sp. & Solidão \\
\hline Pimentão & $\begin{array}{c}\text { Cercosporiose } \\
\text { Pinta preta/ Mancha de Alternaria/ } \\
\text { Alternariose }\end{array}$ & $\begin{array}{l}\text { Cercospora sp. } \\
\text { Alternaria sp. }\end{array}$ & $\begin{array}{l}\text { Solidão } \\
\text { Tabira }\end{array}$ \\
\hline Pimenta de cheiro & $\begin{array}{c}\text { Mancha de cercospora } \\
\text { Ferrugem }\end{array}$ & $\begin{array}{c}\text { Cercospora sp. } \\
\text { Puccinia } \mathrm{sp} .\end{array}$ & $\begin{array}{l}\text { Tabira } \\
\text { Solidão }\end{array}$ \\
\hline Quiabo & $\begin{array}{l}\text { Cercosporiose } \\
\text { Oídio }\end{array}$ & $\begin{array}{c}\text { Cercospora sp. } \\
\text { Oidium spp. }\end{array}$ & $\begin{array}{l}\text { Solidão, Tabira } \\
\text { Solidão, Tabira }\end{array}$ \\
\hline
\end{tabular}

diárias de 25 a $32{ }^{\circ} \mathrm{C}$ e índices de umidade relativa de $40 \%$ e $95 \%$, de acordo com o período do dia e noite, respectivamente. Outro aspecto importante é a umidade conferida pela água de irrigação ou orvalho. Assim, deve-se estar atento ao sistema de irrigação da propriedade. As espécies de Alternaria apresentam conídios altamente resistentes a baixos níveis de umidade, podendo permanecer viáveis por até um ano nestas condições (TÖFOLI et al., 2015). Devido às características semelhantes observadas nos dois grupos de doenças, na implementação do manejo dos cultivos de hortaliças orgânicas ou em fase de transição agroecológica, pode ser indicado ao agricultor técnicas visando à redução da densidade do inóculo inicial, como incorporação dos restos culturais, a rotação de culturas usando plantas não hospedeiras e eliminação de plantas daninhas (REIS et al., 2011; PETHYBRIDGE et al., 2017).

Analisando a distribuição de ocorrência de doenças nos municípios, levando em consideração o número de vezes em que cada espécie foi registrada em cada propriedade/município, foi 


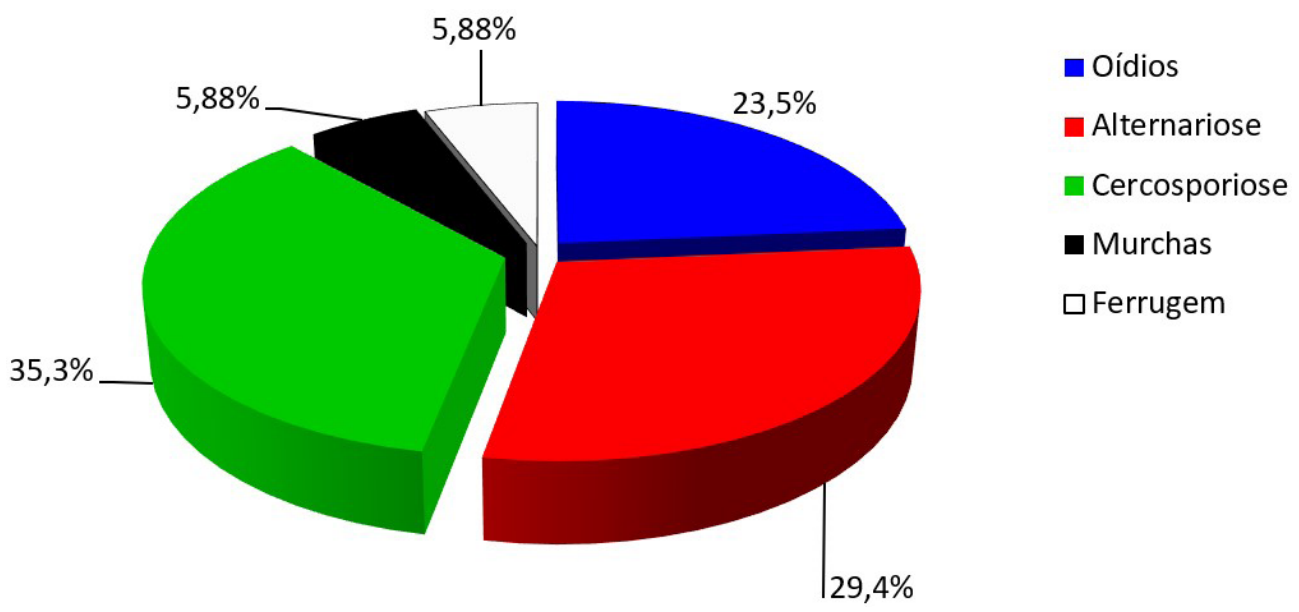

Figura 1. Percentual médio (\%) das principais doenças detectadas nos municípios do Sertão do Pajeú, no período de outubro de 2014 até setembro de 2015.

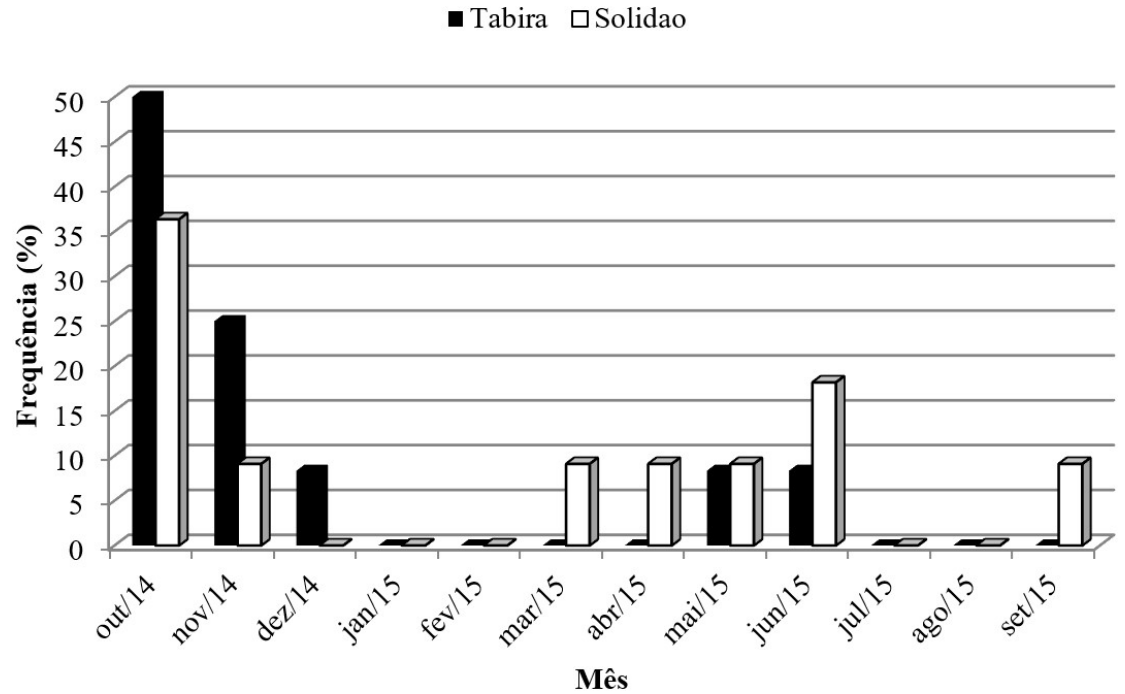

Figura 2. A distribuição da ocorrência de doenças (\%) nos municípios do Sertão do Pajeú, no período de um ano.

observado em Tabira que o percentual de doenças foi maior no período de outubro a dezembro e de maio a junho. Em Solidão, as doenças também ocorreram em dois períodos de frequência distintos de março a junho e setembro a outubro (Figura 2). Gomes et al. (2006) realizaram um levantamento específico para cercosporiose da alface em plantios (convencionais e orgânicos) na Zona da Mata e Agreste Pernambucano, e verificaram que nas áreas de cultivo orgânico, a severidade da doença variou de 0,1 a $22,5 \%$ no período de janeiro a abril, e de 0,0 a $15,1 \%$ de junho a setembro. A severidade média foi significativamente maior no período de janeiro a abril.

Para maioria das doenças, notou-se que não houve uma evolução no decorrer do tempo, exceto para o oídio do quiabeiro (cultura de ciclo longo), que apresentou alta incidência na maioria dos plantios. A doença foi detectada, inicialmente, em ambos municípios, no início de outubro, sendo observada até meados de dezembro em Solidão e janeiro em Tabira. Alguns fatores podem ter contribuído para isso, tais como as fases de cultivo em que se encontravam os plantios nas propriedades no período de avaliação, adubação, densidade de plantio, tipo de irrigação, entre outros. Assim, faz-se necessário um monitoramento dessas doenças por um maior período de tempo. No quiabeiro, o oídio é favorecido por plantios adensados e pelo excesso de adubações nitrogenadas, mostrando-se mais suscetível nas fases de rápido crescimento (BEDENDO, 1995). O uso do espaçamento adequado é muito importante por exercer influência tanto na produção por planta (SETUBAL et al., 2004) quanto na incidência de doenças (BEDENDO; AMORIM, 2011). Durante o desenvolvimento do experimento, foi observado na maioria das propriedades, independente do município, o emprego inadequado da densidade de plantio, exceto em duas propriedades cujos espaçamentos estavam de acordo com os recomendados para cultura, que variam de 0,90 a $1,50 \mathrm{~m}$ entre linhas, e de 0,20 a $0,5 \mathrm{~m}$ entre plantas, podendo ser empregadas duas plantas por covas nos espaçamentos mais largos (ZANIN; KIMOTO, 1980; KAHN et al., 2003).

Os resultados do levantamento de doenças nos cultivos de hortaliças em fase de transição agroecológicas do sertão do Pajeú em Pernambuco mostram a ocorrência dos gêneros fúngicos Fusarium, Puccinia, Oidium, Cercospora e Alternaria. Sendo as cercosporioses e alternarioses mais frequentes 
com percentuais de $35,3 \%$ e $29,4 \%$, respectivamente. Estas informações podem fornecer subsídios para o estabelecimento de um manejo integrado de doenças para as culturas desta região.

\section{Agradecimentos}

Aos agricultores de Tabira e Solidão, que contribuíram e permitiram o desenvolvimento da pesquisa de campo.

\section{Referências}

AGÊNCIA PERNAMBUCANA DE ÁGUAS E CLIMA - APAC. Boletins Climáticos, 2020. Disponível em: <http://www.apac. pe.gov.br/meteorologia/boletins_climaticos_old.php>. Acesso em: 01 jun. 2020.

Alexopoulos, C. J.; Mims, C. W.; Blackwell, M. Introductory mycology. 4th ed. New York: John Wiley \& Sons, 1996. 868 p.

Barnet, H. L.; Hunter, B. B. Illustrated genera of imperfect fungi. 1st ed. Minnesota: Burguess Publising, 1972. 241p.

Barroso, K. A. et al. Diagnóstico de doenças de plantas em hortas agroecológicas em Petrolina-PE. EXTRAMUROS - Revista de extensão da UNIVASF, Petrolina, v. 5, n. 2, edição especial, p. 165-181, 2017.

Bedendo, I. P. Ambiente e doença. In: BERGAMIN FILHO, A.; KIMATI, H.; AMORIM, L. Manual de fitopatologia. 3. ed. São Paulo: Agronômica Ceres, v. 1, 1995. p. 331-341.

Bedendo, I. P.; Amorim, L. Ambiente e doença. In: AMORIM, L.; REZENDE, J.A.M.; BERGAMIN FILHO, A. Manual de fitopatologia. 4. ed. São Paulo: Agronômica Ceres, v. 1, 2011. 704 p.

Bettiol, W. Controle alternativo de doenças na agricultura orgânica. Summa Phytopathologica, v. 30, n. 1, p. 158-160, 2004.

Cuenca, M. A. G. Realocação espacial da agricultura no âmbito de microrregiões: Pernambuco, 1990 e 2004. Aracaju: Embrapa Tabuleiros Costeiros, 2007.

Gomes, A. M. A. et al. Intensidade da cercosporiose da alface em cultivos convencionais e orgânicos em Pernambuco. Summa Phytopathologica, Botucatu, v. 32, n. 4, p. 384-385, 2006.

INSTITUTO BRASILEIRO DE GEOGRAFIA E ESTATÍSTICA-IBGE. Levantamento sistemático da produção agrícola. Sistema IBGE de Recuperação Automática - Sidra. Disponível em: $<$ https:// sidra.ibge.gov.br/home/lspa/brasil>. Acesso em: 01 jun. 2020.

Kahn, B. A.; Wu, Y.; Maness, N. O. Densely planted okra for destructive harvest: III. Effects of nitrogen nutrition. HortScience, Alexandria, v. 38, p. 1370-1372, 2003.

King, J. E. Cereal survey methodology in England and Wales. In: Teng, P. S.; Krupa, S. V. (Ed.). Crop loss assessment which constrain production and crop improvement in agriculture and forestry. Minnesota: University of Minnesota, 1980. p. 124-133.
Menezes, M.; ASSIS, S M. P. Guia prático para fungos fitopatogênicos. 2. ed. Recife: Imprensa Universitária, 2004. 187 p.

Nelson, P. E.; Toussoun, T. A.; Marasas, W. F. O. Fusarium species: na illustrated manual for Identification. Pennsylvania: The Pennsylvania State University, 1983. 193 p.

BRASIL. MINISTÉRIO DO DESENVOLVIMENTO AGRÁRIO. SECRETARIA DE DESENVOLVIMENTO TERRITORIAL. Plano Territorial de Desenvolvimento Rural Sustentável do Sertão do Pajeú, Brasília, 2011.

Pereira, R. B.; Pinheiro, J. B. Manejo integrado de doenças em hortaliças em cultivo orgânico. Brasília: Embrapa Hortaliças, 2012. (Circular Técnica, n. 111), 12 p.

Peruch, L. A. M.; Michereff, S. J.; Araújo, I. B. Levantamento da intensidade da alternariose e da podridão negra em cultivos orgânicos de brássicas em Pernambuco e Santa Catarina. Horticultura Brasileira, Brasília, v. 24, n. 4, p. 464-469, 2006.

Pethybridge, S. J.; Vaghefi, N.; Kikkert, J. R. Management of Cercospora leaf spot in conventional and organic table beet production. Plant Disease, Saint Paul, v. 101, p. 1642-1651, 2017.

Reis, E. M.; Casa, R. T.; Bianchin, V. Controle de doenças de plantas pela rotação de culturas. Summa Phytopathologica, Botucatu, v. 37, n. 3, p. 85-91, 2011.

Sediyama, M. A. N.; Santos, I. C.; Lima, P. C. Cultivo de hortaliças no sistema orgânico. Revista Ceres, Viçosa, v. 61, p. 829-837, 2014.

Setubal, J. W.; Zanin, A. C. W.; Sittolin, I. M. Hábito de florescimento do quiabeiro cv amarelinho em função da população de plantas. Horticultura Brasileira, Brasília, v. 22, (Suplemento CD- ROM), 2004.

Silva, K. E. Levantamento de doenças da alface e da couve em produção urbana de Lavras (MG) e Campina Grande (PB). 2015, 66 f. Dissertação (Mestrado em Agronomia)-Universidade Federal de Lavras, Lavras, 2015.

Silva, A. M. F. et al. Levantamento da intensidade da podridão-mole em alface e couve-chinesa em Pernambuco. Caatinga, Mossoró, v. 20, n. 2, p. 84-93, 2007.

Solel, Z. Survival of Cercospora beticola, the causal agent of sugar beet leaf spot, in Israel. Transactions of the British Mycological Society, Cambridge, v. 54, p. 504-506, 1970.

Töfoli, J. G.; Domingues, R. J.; Ferrari, J. T. Alternaria spp. em oleráceas: sintomas, etiologia, manejo e fungicidas. O Biológico, São Paulo, v. 77, n. 1, p. 21-34, 2015.

Versyple, N. I. et al. Microrregião Pajeú: economia, clima e desenvolvimento da agricultura através de modelo digital do terreno. Revista GEAMA, Pernambuco, v. 1, n. 1, p. 16-30, 2015.

Zanin, A. C. W.; Kimoto, T. Efeito da adubação e espaçamento na produção de sementes do quiabeiro. Revista Brasileira de Sementes, Brasília, v. 2, p. 105-112, 1980.

Recebido: 06 jan. 202 Aprovado: 06 jan. 2021 